\title{
ACTITUDES FALANGISTAS ANTE LAS ELECCIONES MUNICIPALES (1948-1957)
}

\author{
José Antonio Miranda Encarnación \\ Universitat Pompeu Fabra \\ Juan Francisco Pérez Ortiz \\ Universidad de Alicante
}

\begin{abstract}
"No creemos que nuestra aspiración sea convertimos en unas vestales del sufragio puro y partiendo de esta base es verdaderamente fácil y hasta cómodo respetando exteriormente los preceptos legales y madurando las cosas y los casos con tiempo y reflexión, llevar las aguas al molino propio. Téngase en cuenta que los Gobemadores, Jefes Provinciales y Alcaldes son de designación directa por el Gobiemo y en estas condiciones con unas Mesas cuidadas y un equipo hábil, es tanto como jugar con un adversario cuyas cartas se traslucen".
\end{abstract}

Jefe Provincial del Movimiento de Gerona, 1955.

\section{INTRODUCCION}

La celebración de elecciones municipales a partir de 1948 constituyó una de las piezas del complejo entramado de elecciones no-competitivas que el franquismo utilizó con el fin de ofrecer una imagen más aceptable ante los vencedores de la II Guerra Mundial. Aunque no se dispone de estudios globales sobre las elecciones municipales, similares a los existentes para las elecciones a Cortes, son muy conocidos ciertos aspectos puntuales (confusión normativa, abstencionismo, mecanismos de manipulación), pero centrados en la última fase de la dictadura ${ }^{2}$.

En estas páginas realizaremos una aproximación a lo que fueron las actitudes generales dentro de la estructura política del Movimiento respecto a unas elecciones que, si bien se les ofrecían como un terreno exclusivo, fueron percibidas en no pocas ocasiones como una amenaza potencial a la hegemonía que los falangistas disfrutaban en la política local. Este acercamiento a la opinión falangista ha sido posible, en lo

\footnotetext{
${ }^{1}$ Este artículo es una versión ampliada de la comunicación que presentamos al Congreso Internacional "El Régimen de Franco (1936-1975)", organizado por la UNED de Madrid en mayo de 1993.

${ }^{2}$ Las siguientes obras constituyen una muestra de la bibliografía existente: RUIZ DE AZUA ANTON, Miguel Angel (1986- 87): Las elecciones a las Cortes de Franco, 1942-1975. Tesis doctoral, Universidad Complutense. VANACLOCHA, F. J. (1977): "Las elecciones de representación familiar en las Cortes españolas (1967-1974), como elecciones no-competitivas". Cuadernos Económicos de ICE, 1, pp. 59-76. SOLE TURA, Jorge (1972): "Elecciones municipales y estructura del poder político en España". En Estudios de Ciencia Política y Sociología. Homenaje al profesor Ollero, Madrid, pp. 785-800. VIDAL BENEYTO, José (1966): Elecciones municipales y referéndum. Nota sobre las elecciones municipales por el tercio familiar del Ayuntamiento de Madrid del 20.11.1966. Madrid: Imp. Tanagra. GIL-ROBLES Y GIL DELGADO, José María (1971): "1971: Año electoral. Análisis de una legislación". Cuadernos para el Diálogo, 92, 93, 94, pp. 19-22, 13-14, 17-19 respectivamente.
} 
esencial, gracias a la documentación conservada en la sección de Presidencia del Archivo General de la Administración de Alcalá de Henares. Entre los fondos de la Secretaría General del Movimiento se encuentra un importante volumen de información acerca de las elecciones municipales, destacando las instrucciones para su preparación, circulares de muy diverso contenido, informes previos y posteriores a su celebración y resúmenes sobre los candidatos elegidos.

\section{PROBLEMAS INTERNOS Y ELECCIONES MUNICIPALES: 1948}

La primera convocatoria de elecciones municipales, realizada en 1948, coincidió con un momento delicado para el franquismo, aunque ya se había superado la peor fase de aislamiento internacional. Fue en el verano de 1945 cuando, claramente forzado por los acontecimientos, Franco anunció que se celebrarían elecciones municipales, presentándolas como el paso inicial que conduciría a una progresiva apertura política. Esta decisión coincidió con el final de la II Guerra Mundial, cuando se hizo aconsejable la adopción de medidas supuestamente liberalizadoras. Repetidamente se ha señalado que estas mismas circunstancias fueron decisivas en la promulgación de la Ley de Bases del Régimen Local o del Fuero de los Españoles, que pretendió ser un código de derechos civiles.

A partir de 1946 se pudo contar con un rudimentario censo electoral, que ya fue utilizado en el referéndum sobre la Ley de Sucesión en 1947. Y finalmente, en noviembre de 1948 se iniciaron las elecciones, en las que de forma sucesiva se renovaron por mitades, cada tres años, los representantes de los coloquialmente conocidos como "tercio familiar", "tercio sindical" y "tercio corporativo". De manera regular, en 1951, 1954 y 1957, dentro del periodo que abarca este artículo, se repitió la convocatoria electoral. Una de las constantes de este periodo fue la silenciosa pugna sostenida entre falangistas y católicos por ostentar la supremacía dentro del equilibrio de poderes que cimentaba el régimen. En ese sentido, el desarrollo de las elecciones en 1948 corrió paralelo a lo que pudo interpretarse como una recuperación o reforzamiento temporal de la influencia falangista, motivado tanto por un deseo de acallar las voces de protesta surgidas en las filas falangistas por la propia convocatoria de elecciones, como por el intento de contrapesar la creciente influencia de monárquicos y católicos ${ }^{3}$.

En efecto, la vocación totalitaria de la ideología falangista provocó que el solo anuncio de la celebración de elecciones levantara una oleada de indignación. Los sectores más rígidos en sus concepciones y los líderes, no escasos, que consideraban irrenunciables sus compromisos políticos con el ideal falangista, hicieron patente un estado de ánimo poco predispuesto a que unas elecciones "inorgánicas" manchasen la pureza del régimen, precisamente en la administración local, donde los falangistas

\footnotetext{
${ }^{3}$ Para un análisis pormenorizado de la agitación interna entre los falangistas veáse ELLWOOD, Sheelag (1984): Prietas las filas. Historia de Falange Española, 1933-1983. Barcelona, Crítica.
} 
disfrutaban de mayor grado de control ${ }^{4}$. La reaparición de la figura del Secretario General del Movimiento, en la persona del Ministro de Justicia, Raimundo Fernández Cuesta, fue el elemento que encarnó hasta qué punto la presión falangista había tenido éxito (aunque el cargo no recuperó la categoría ministerial hasta 1951). Esto significaba que el partido volvía a asumir un cierto protagonismo y que, por tanto, no debía temer nada de las elecciones, pero también reflejaba la voluntad de controlar a las díscolas huestes falangistas con la figura de una jerarquía máxima en torno a la cual se aunarían todos los esfuerzos y se reforzaría la quebradiza disciplina interna.

\section{DESARROLLO DE LAS ELECCIONES Y CRITICAS FALANGISTAS}

Antes de comenzar a analizar los aspectos más interesantes de las elecciones, hay que destacar por su notable interés, de entre la abundante documentación disponible ${ }^{5}$, los informes redactados por los Jefes Provinciales del Movimiento a comienzos de 1955 como respuesta a una circular remitida por la Delegación Nacional de Provincias ${ }^{6}$. En esta circular se había solicitado información detallada sobre el desarrollo de las elecciones celebradas a finales de 1954, centrándose sobre tres grandes temas: los candidatos a las elecciones y los problemas planteados por su proclamación, la actitud de los afiliados al Movimiento y de la población en general ante las elecciones $y$, por último, la posibilidad de establecer cambios en el mecanismo electoral.

De estos informes tan sólo faltan los correspondientes a siete provincias (Avila, Jaén, Palencia, Salamanca, Santa Cruz de Tenerife, Valladolid y Vizcaya), por lo que puede considerarse, con ciertas reservas, que las opiniones recogidas son bastante significativas (en el caso de ciertas provincias se cuenta además con documentos complementarios que permiten contrastar y revisar los datos ofrecidos). En determinados informes se aprecia una redacción excesivamente cauta -ya que no se pronuncian claramente sobre las alternativas planteadas- o bien se trasluce un tono justificativo y exculpatorio de la labor realizada por el respectivo Jefe Provincial. Si bien en ocasiones se aprecia un cumplimiento rutinario de la tarea, en general se aprovecha la ocasión brindada para expresar puntos de vista contrastados entre los

\footnotetext{
${ }^{4}$ La diplomacia británica prestó una considerable atención al anuncio, preparación, desarrollo y resultados de las elecciones en 1948. Son particularmente interesantes las observaciones recogidas en los siguientes informes: Public Record Office, FO/371/73.356: Z/6496 (10.8.48), Z/9230 (11.11.48), Z/9634 (25.11.48) y $\mathrm{Z} / 10081$ (9.12.48). Se subrayó sobre cualquier otro aspecto el estricto control ejercido desde el Ministerio del Interior y los Gobiemos Civiles.

${ }^{5}$ Se conserva en el Archivo General de la Administración. Presidencia del Gobierno, Secretaría General del Movimiento, Delegación Nacional de Provincias. Han sido consultadas las cajas 300, 301, 304. 318,319 y 321 .

${ }^{6}$ En adelante, cuando no se mencione la fuente se entenderá que los datos provienen de los informes citados, que se encuentran en la caja 304.
} 
mandos provinciales $\mathrm{y}$, lo que constituye el elemento más valioso, para exponer quejas con bastante crudeza.

Como cabía esperar, el desarrollo de las elecciones, desde sus fases más tempranas, era dirigido y supervisado desde el respectivo Gobierno Civil de cada provincia. Los preparativos se iniciaban a comienzos del año en el que correspondía celebrar elección y se intensificaban, lógicamente, a finales del verano, ya que la votación tenía como núcleo central el mes de noviembre. Con el fin de atender cualquier contingencia se establecía en los Gobiernos Civiles un servicio de asesoramiento y vigilancia al que podían acudir los Jefes Locales en demanda de ayuda. Además, una serie de inspectores, delegados por el gobernador civil, recorrían las provincias, atendiendo sobre el terreno los posibles conflictos e informando sobre la idoneidad de los candidatos.

En las instrucciones se insistía machaconamente en la necesidad de que los militantes se comportaran en todo momento, y en especial en lo que concernía a la presentación de candidatos, con absoluta obediencia respecto a las indicaciones de los mandos. Preocupaba de manera profunda -a pesar de que era una posibilidad ciertamente remota- la concurrencia de candidatos ajenos a la estricta órbita de Falange y en consecuencia se ordenaba informar sin dilaciones al Jefe Provincial, para que éste impidiese su proclamación definitiva. No parecían estar mucho más tranquilos los jerarcas falangistas con la posibilidad de que se presentaran espontáneamente falangistas que no contaban con su aquiescencia. Se les advertía que cualquier falta de disciplina sería sancionada con el mayor rigor, lo que equivalía a la expulsión inmediata de la organización y a la inhabilitación para ejercer cargos políticos. Se pretendía evitar algo que, a tenor de la frecuencia con que se menciona y del empeño que se pone en prevenirlo, tuvo que ser un fenómeno significativo y preocupante: el surgimiento de disputas y enfrentamientos directos entre falangistas ${ }^{7}$.

La capacidad de maniobra de los Jefes Provinciales para conseguir una adecuada conducción de las elecciones era muy considerable, ya que además de los mecanismos que se les atribuían en los textos legales ${ }^{8}$ podían desplegar en la práctica -con discreción- otras medidas de control. Aún así, la voluntad de dominio absoluto de los falangistas se reflejo en el hecho de que buena parte de los informes sobre las elecciones de 1954 solicitasen de una u otra forma "armas más eficaces para

\footnotetext{
${ }^{7}$ Un caso de enfrentamiento enconado se produjo en Alicante en 1948, al presentarse candidaturas integradas por falangistas que no contaban con el beneplácito del aparato del partido en las principales ciudades de la provincia (AGA, Sección de Gobemación, caja 3523). Las referencias a la ruptura de la cordialidad y la armonía internas fueron constantes, por lo que no es de extañar que a lo largo de todas las convocatorias electorales una de las consignas omnipresentes fuese la conocida "Somos movimiento que une y no partido que divide".

${ }^{8}$ Pueden consultarse los siguientes textos: ELECCIONES MUNICIPALES (1957): Recopilación de normas para su celebración, complementadas con el texto vigente de la ley electoral, por la redacción de La administración práctica. Barcelona: Bayer. MINISTERIO DE LA GOBERNACION (1970): Legislación electoral española. Anotaciones y concordancias. Madrid. SOUTO NAVEIRA, Marcelino (1966): Guía práctica electoral. Santander. Para una aproximación puede recurrirse a las cajas ya reseñadas del AGA, ya que las instrucciones dirigidas a los gobemadores solían ir acompañadas de un resumen de las disposiciones legislativas más relevantes.
} 
encauzar las elecciones en todos sus tercios" (especialmente en el de cabezas de familia) ${ }^{9}$. Se reclamo un grado mayor de discrecionalidad para el Jefe Provincial en cuanto a la proclamación de candidatos, ya fuese a través de reforzar la facultad para vetarlos (en este punto se pedía la sanción legal de un hecho que ya se daba), o bien exigiéndoles con mayor rigor un certificado de adhesión o una serie de requisitos de gran complejidad (con el evidente fin de imposibilitar materialmente la presentación de candidatos molestos). Ante el caso poco probable de que consiguiera presentarse y triunfar un candidato indeseado, se reclamaron mayores posibilidades y mayor rapidez para revocar y desposeer a los concejales ya elegidos. $Y$ aunque era difícil, se solicitó que la Junta de Elecciones estuviese más sujeta al mando político. No se quería dejar ningún resquicio por el que se filtrara el menor asomo de semioposición $o$ de independencia frente al dominio falangista.

Se prestó una atención especial a la idoneidad -que en este contexto sólo podía ser la lealtad absoluta- de los componentes de dos organismos claves en el desarrollo de las elecciones: las Juntas Municipales del Censo y las mesas electorales. En cuanto a las primeras no había lugar para la duda, porque tal como señalaba un Jefe Provincial "dada la designación de las Juntas Municipales, se deberá conseguir siempre que estas sean adeptas", con lo que desaparecían potenciales peligros. En la misma línea se pronunciaba un documento preparatorio de las elecciones de 1954 en el que se recomendaba tener un particular cuidado para que en las Juntas Municipales del Censo tuviesen una posición predominante falangistas de "bien probado espíritu y alto sentido de la disciplina". Como en la inmensa mayoría de las localidades la Jefatura Local del Movimiento y la Alcaldía recaían en la misma persona, no podía darse un mejor punto de partida para el control de las Juntas Municipales del Censo, ya que estaban presididas por los Alcaldes. De igual manera y respecto a las mesas electorales, se resaltó continuamente la importancia que, ante distintas eventualidades, tenía su composición. Una circular de 1957 a los Jefes Locales y Alcaldes no podía ser más explícita respecto a la designación de los posibles miembros de las mesas:

"Con la debida antelación, con la mayor discreción y tacto, en estrecha colaboración con la Alcaldía, confeccionarás las referidas listas, cuidando de buscar entre los electores, elementos idóneos y seguros que atiendan a cualquier sugerencia del Mando, pues ha de cuidarse muy especialmente de que ante una posible abstención parcial del electorado se hiciese preciso el aumento proporcional de los votos emitidos a favor de cada uno de los candidatos" ${ }^{\prime 10}$.

Se ha introducido con la cita anterior un tema, el del volumen de participantes, de gran relevancia en la valoración de las elecciones municipales. Desde las instancias oficiales se sostuvo siempre que éstas carecían de significado o contenido político y se limitaban a constituir un acto de carácter puramente administrativo en el que todos los ciudadanos estaban involucrados. Lo cierto es que a nadie, ni

\footnotetext{
'AGA, PG, SGM, caja 321.

${ }^{10}$ AGA, PG, SGM, caja 318.
} 
siquiera al propio aparato falangista, se le ocultó el cariz político que adoptaban, a pesar de sus limitaciones, por constituir la única vía que permitía manifestar cierta disidencia. Durante el franquismo cada elección se convertía en un plebiscito para el régimen. Este necesitaba cifras muy elevadas de participación, para reducir al mínimo el número de las abstenciones, ya que éstas podían identificarse de forma genérica con los descontentos y opositores. De ahí las coacciones ejercidas para que la población se acercase a las urnas y la obsesión por reflejar en las cifras oficiales porcentajes muy elevados de votantes. Las autoridades políticas se veían sujetas a la necesidad de "mover el cuerpo electoral" el día de la votación, mientras que anteriormente debían hacer todo lo posible para que las elecciones suscitasen el menor grado posible de movilización política. El camino para conseguir el nivel de participación deseado comenzaba por el ejercicio de todo tipo de coacciones psicológicas, pasaba por las amenazas directas y podía finalizar, si era necesario, con un simple retoque de las cifras oficiales. De este modo, se insistió en la obligatoriedad del voto, pero sobre todo se recordaron los posibles perjuicios que podía acarrear no disponer del correspondiente certificado de haber votado. En este sentido es significativo que en diversas provincias los Jefes Provinciales reconocen y afirman explícitamente que el único motivo para votar era el temor a las sanciones ${ }^{11}$.

No se dispone de noticias sobre niveles reales de participacion y ante la nula fiabilidad de los datos oficiales sólo se han apuntado algunas estimaciones. Sin embargo, la convicción de que el régimen inflaba sistemáticamente las cifras de votantes se ve apoyada por algunas afirmaciones (recuérdese la cita anterior) y datos diseminados a lo largo de los informes sobre las elecciones de 1954. En primer lugar se reconocía que la opinión pública en general no creía los datos oficiales, de igual manera que desconfiaba del conjunto del proceso electoral. Así el Jefe Provincial de Guipúzcoa sostenía que en lo referente al conjunto del país "los porcentajes superiores al $80 \%$ no convencen absolutamente a nadie, teniendo todos la seguridad, aunque quizás ello no sea cierto, de que la obtención de estos porcentajes es totalmente ajena a las urnas, o que en todo caso se han introducido más papeletas que votantes efectivos hubo". Sin facilitar datos concretos, el Jefe Provincial de Badajoz informaba que la opinión pública desfavorable se traducía en unos contingentes de votantes reducidos "no obstante los estímulos empleados". En algunas poblaciones de Ciudad Real sólo había acudido el $16 \%$ de los votantes y allí donde los porcentajes eran elevados se había debido exclusivamente a problemas de

${ }^{11}$ Las amenazas de retirada de la cartilla de racionamiento a aquellos que no hubiesen votado se utilizaron ya en 1947. Dada la situación de penuria generalizada no es difícil suponer hasta qué punto muchas personas se sintieron animadas a votar. Como ejemplo de la propaganda oficial, reproducimos el texto de los carteles que se exhibieron en la vía pública en Vizcaya: "VOTA y pide certificado de haber votado. PUEDE HACERTE FALTA": "Tu obligación de español es VOTAR el día 21": "Si tienes voto VOTA, si no lo tienes haz propaganda para que voten los que lo tengan"; "FRANCO HA DICHO: las instituciones municipales son la rueda más importante de la vida política de la Nación": "La vida municipal depende DE LOS CONCEJALES QUE TU ELIJAS"; "VOTA a quien quieras, PERO VOTA. cumple con tu deber"; "VOTAR no es HACER POLITICA, es defender tus intereses". AGA, PG, SGM. caja 304, memoria sobre las elecciones municipales celebradas en Vizcaya, 1954. 
ámbito local que estimulaban la participación. En Las Palmas las cifras oficiales señalaban un $67 \%$ de votantes, pero realmente no había superado el $40 \%$. De igual manera, en Orense no votó más del $50 \%$ del censo mientras que en Sevilla capital sólo alcanzó el $52 \%$

En definitiva, lo que demostraban los datos anteriores era el escasísimo interés que la opinión pública manifestaba por las elecciones, que eran consideradas como una pantomima oficial. En este punto, al describir el ambiente general como apático, frío, indiferente y desfavorable, se da una identificación casi absoluta en los informes sobre las elecciones de 1954. Estas se convirtieron en un motivo de burla para la población, convencida de que eran ampliamente manipuladas y de que si los resultados no coincidían con los esperados por las autoridades franquistas era inevitable un pucherazo. En Granada la actitud ciudadana fue "mala y llena de mordaz ironía", porque se conocieron los nombres de los concejales elegidos antes de celebrarse la votación (el Gobernador no especificó en su informe si también se supo con antelación el número concreto de votos que iba a obtener cada candidato).

Un elemento adicional debe ser considerado a la hora de calibrar el impacto -y el descrédito entre la población- de las elecciones municipales durante estos años. Siempre que se tuvo ocasión y frente a instrucciones precisas que recomendaban no utilizarlo, se recurrio al artículo 55 del Reglamento de Organización, Funcionamiento y Régimen Jurídico de las Corporaciones Locales. Este no era otra cosa que una reedición del artículo 29 de la Ley Electoral de 1907, por lo que su aplicación equivalía a la elección automática de los candidatos proclamados cuando éstos no superasen el número de puestos vacantes. En las elecciones de 1954 se aplico generosamente en algunas provincias, afectando sobre todo a municipios de pequeño tamaño. En Vizcaya, Lugo, Baleares y Valencia, con 112, 67, 65 y 264 municipios, el artículo 55 evitó la celebración de las elecciones en 87, 56, 25 y 50 ayuntamientos respectivamente. En Cáceres se aplicó en el $75 \%$ de los municipios. Una investigación detallada de este aspecto podría revelar que las elecciones se celebraron en algunos momentos y provincias de manera casi testimonial ${ }^{12}$.

Hay suficientes motivos para creer que las afirmaciones de los Jefes Provinciales sobre las actitudes de la opinión pública se ajustaban bastante a la realidad. Pero el hecho de que no matizasen ni ocultasen en absoluto este indicador del grado de descontento de la población, se debía a que esta situación podía beneficiarles en sus batallas particulares dentro del régimen. Asimismo podían realizar una identificación entre el malestar público y sus continuas quejas sobre la inutilidad y los peligros de las elecciones, en estrecha relación con su radicalismo antidemocrático. En su opinión las elecciones sólo eran una concesión de cara a la opinión pública extranjera, un elemento que pretendía favorecer la presencia exterior del régimen.

${ }^{12}$ Fl Jefe Provincial de Teruel, de manera un tanto ambigua, parece indicar que en la mayor parte de la provincia no se celebraron elecciones en 1951 y 1954. M. Marín ofrece unos datos reveladores sobre la provincia de Barcelona: sobre un total de 309 municipios, en 1948 se celebraron elecciones en tan sólo 43, en 1951 en 12, en 1954 en 1, en 1957 en 10 y en 1960 en 2. MARIN I CORBERA, Martí (1993): "Franquismo y poder local. La puesta en marcha de la democracia orgánica municipal en la Cataluña urbana, 1945-1957". En VV.AA.: El Régimen de Franco (1936-1975). Madrid: UNED, pp. 569-579. 
Generaban multitud de problemas y dado que no era fácil "reformar lo que no tiene arreglo", sencillamente, se abogaba por su abolición, por la vuelta al sistema de comisiones gestoras, por la designación directa por parte de las jerarquías. Con el fin de subrayar el rechazo visceral hacia lo que peyorativamente denominaban "sufragio inorgánico" se hacían continuas alusiones al discurso fundacional de Falange, en el que José Antonio señaló que el mejor destino posible de las urnas era su destrucción. Como propuesta, desde algunas provincias se recomendó el corporativismo pleno o al menos la eliminación del tercio familiar. En efecto, era el primer tercio el que tenía un mayor contenido político y podía dar lugar a situaciones más conflictivas. Sobre los posibles candidatos se ejercía una rigurosa inspección que determinaba si se les concedía permiso para presentarse definitivamente, cuestión harto difícil en el supuesto de encontrarse en el amplio campo de los "enemigos" o "independientes".

En el segundo tercio, de representación sindical, la elección se realizaba a través de compromisarios. A pesar de las garantías que parecía ofrecer sobre los candidatos, en 1954 se produjo una llamada de atención por parte de algunos Jefes Provinciales exponiendo un fenómeno que se venía gestando desde 1949. Se trataba de que el PCE estaba desarrollando una importante labor para infiltrar a sus militantes en la organización sindical. Así, los Gobernadores Civiles, además de reclamar un mayor grado de control efectivo de las elecciones por este tercio, denunciaron el peligro que representaba la presencia de elementos de ideología izquierdista que, superando el ostracismo de posguerra, se proponían llegar hasta los municipios utilizando los sindicatos como puente. Desde Guipúzcoa se señalaba como un peligro futuro el que "cada vez conocen mejor sus derechos todas las Juntas sociales y económicas y no es de suponer que esté muy lejano el día en que obren con absoluta libertad y completamente desconectados del Mando político".

Finalmente, el llamado "Tercio de entidades económicas, culturales y profesionales y vecinos de mayor prestigio" no planteaba ningún tipo de problemas. El Jefe Provincial proponía una lista de candidatos y votaban el resto de concejales, tanto los recién designados como los que no habían sido renovados. Popularmente era conocido como "el tercio del Gobernador Civil" o el "de consolación" porque se solía compensar a algunos candidatos no electos del primero y segundo tercio designándolos para éste.

\section{CONCLUSIONES}

A pesar de los problemas que pudieron plantearse entre 1948 y 1957, no sería acertado hablar de un estado de rebeldía latente dentro del núcleo falangista. Como hemos podido comprobar, las quejas en cuanto a la celebración de estas pseudoelecciones, que en principio se convirtieron para los falangistas en un símbolo de los derroteros impuros que tomaba el régimen, no fueron excesivamente radicales (en parte porque comprendían el papel de las elecciones en la estrategia de recuperación de prestigio internacional del régimen). Se discutieron aspectos puntualés y se llegó a plantear la supresión total de las elecciones, en línea con lo que pretendía ser una 
vuelta política hacia los orígenes, pero en ningún momento se cuestionó la lealtad básica al régimen.

Además de las fisuras que se podían abrir en su hegemonía política en el terreno local, las elecciones municipales generaban malestar dentro del aparato falangista por diversos motivos. En primer lugar, constituían una ocasión inmejorable para que se manifestaran -cuando estaban soterradas- o surgiesen, tensiones internas a nivel local. Asimismo, aunque no era necesaria una excesiva movilización del aparato del partido, éste se encontraba ya lo suficientemente burocratizado, como para lamentarse de las perturbaciones que originaban la preparación y la celebración de las elecciones. Por último, cabe considerar que con las elecciones se ponía en evidencia el escaso entusiasmo de la opinión pública hacia el régimen y hacia las casi nulas posibilidades de participación que éste, graciosamente, concedía. En ocasiones la capacidad de autoengaño fue extraordinaria y se afirmó con complacencia que el espíritu falangista había conseguido inculcar en los españoles una repulsión instintiva hacia las elecciones. Pero en la mayor parte de los testimonios conservados se reconocía que la población no se dejaba engañar, que la indiferencia generalizada era una manifestación callada de rechazo y que se votaba en buena parte para evitar posibles represalias. 